

\title{
O Taller como prática do processo de cidadania
}

\section{El Taller como práctica del proceso de ciudadanía Workshops as a Practice of the Citizenship Process}

\author{
Cristhian Moreira Brum*
}

\section{Resumo}

Esta é a apresentação de mais uma experiência do Taller $^{1}$, com a proposta de dar continuidade às reflexões que mostram o Taller como forma de aprender a ser cidadão, onde, com vistas à interdisciplinaridade, detalha a aplicação e a análise de desenvolvimento local, buscando adaptar ou criar espaços em função das necessidades dos indivíduos. Esta experiência na Arquitetura está vinculada às questões políticas e sociais do lugar onde se propõe desenvolver o Taller. Vivemos em um mundo onde os direitos humanos estão presentes em todas as esferas articuladoras das políticas públicas que criem formas e ferramentas para promover o bem-estar dos sujeitos e sua participação ativa em decisões comuns à sua comunidade. Portanto o $2^{\circ}$ Taller Vertical Internacional em Frederico Westphalen, RS é uma forma de dar continuidade ao processo de cidadania dentro das atividades acadêmicas do Curso de Arquitetura e Urbanismo, mantendo viva a reflexão sobre os espaços públicos.

\section{Palavras-chave}

Taller; cidadania; espaços urbanos; arquitetura; urbanização

\footnotetext{
* Professor do Departamento de Ciências Sociais Aplicadas da Universidade Regional Integrada do Alto Uruguai e das Missões-URI Campus de Frederico Westphalen

1 Entendido como Oficina
} 


\section{Palabras clave}

Taller; ciudadanía; espacios urbanos; arquitectura; urbanización

\section{Keywords}

Taller; citizenship; urban spaces; architecture; urbanization

\section{Resumen}

El presente artículo expone otra experiencia del Taller, queriendo continuar las reflexiones que devela el mismo como forma de aprender a ser ciudadano, donde, con miras a la interdisciplinariedad, detalla la aplicación y análisis del desarrollo local, tratando de adaptarse o crear espacios para las necesidades de los individuos. Esta experiencia en la arquitectura está vinculada a cuestiones políticas y sociales del lugar donde se propone desarrollar el Taller. Vivimos en un mundo donde los derechos humanos están presentes en todas las esferas de coordinación de las políticas públicas que crean formas y herramientas para promover el bienestar de los sujetos y su participación activa en las decisiones de sus comunidades. Por lo tanto, el $2^{\circ}$ Taller Vertical Internacional en Frederico Westphalen/RS, es una forma de continuar el proceso de ciudadanía en las actividades académicas de la Arquitectura y Urbanismo, manteniendo viva la reflexión sobre los espacios públicos.

\section{Abstract}

This is the presentation of another experience Taller with the proposal to continue the reflections that show the Taller as a way of learning to be a citizen, where, with a view to interdisciplinarity, details the application and local development analysis, seeking to adapt or create spaces for the needs of individuals. This experience in architecture is linked to political and social issues of the place where it is proposed to develop the Taller. We live in a world where human rights are present in all spheres of coordinating public policies that create forms and tools to promote the welfare of the subjects and their active participation in common to their community decisions. So the 2 nd Vertical Taller International in Frederico Westphalen, RS is a way of continuing the process of citizenship within the academic activities of the Architecture and Urbanism course, keeping alive the reflection on public spaces. 


\section{Considerações iniciais}

Este texto pretende trazer um avanço na reflexão de questões emergentes na sociedade atual, destacando o papel do arquiteto como sujeito social que atua no ensino, construindo uma reflexão a respeito dos espaços urbanos na perspectiva de atenção ao exercício da cidadania. Para isso, se institui o Taller, como inserção de uma prática que integre os espaços públicos aos estudos de arquitetura e urbanismo. Segundo Brum e Callai (2015) esta prática busca adaptar ou criar os espaços em função das necessidades dos indivíduos, como uma proposta de desenvolvimento local que precisa ter objetivo e espaço geográfico próprio, estando sua a existência vinculada às questões políticas e sociais de um lugar.

O Taller de projetos tem o objetivo de infundir e integrar o aluno em um palco e em uma dinâmica de trabalho, de criatividade, de visão e de abordagem ao projeto arquitetônico, para enriquecer os modos de representação de mesma linguagem (Sánchez, 2012). Para este autor, esta metodologia se desenvolve sob o workshop do projeto, com atividades e metas que fazem um cenário ideal que promove a experiência inicial no uso e familiaridade de uma língua ou forma de expressão gráfica (típico da arquitetura) com formas de abordagem e a prática da arquitetura.

O Taller, além de inserir o professor arquiteto e urbanista em um patamar pedagógico de teoria-prática em disciplinas de projeto de arquitetura, também proporciona uma forma interdisciplinar de pensar os problemas da arquitetura e urbanismo ao acadêmico, fazendo-o propor soluções com fins na socialização do conhecimento. É um compromisso firmado entre as ações acadêmicas com fins na transformação da realidade urbana e regional do território, fortalecendo a relação professor-acadêmico em um objetivo comum de proporcionar novos paradigmas para a resolução dos problemas da sociedade.

Neste sentido, na resolução de problemas sociais no contexto dos espaços urbanos, também devemos considerar as afirmações de Santos (1988) sobre os espaços geográficos, em que destaca que todos os espaços são geográficos porque são determinados pelo movimento da sociedade, das pessoas e da produção, porém, tanto a paisagem quanto o espaço resultam de movimentos superficiais e de fundo da sociedade, uma situação real de funcionamento unitário, um esquema de relações, formais, funcionais e de sentidos.

É interessante considerar que Harvey (2013) pensa o arquiteto como o profissional inserido nos processos de construção e elaboração de espaços, utópicos ou não. Esses espaços são moldados para conferir utilidade social, bem como significados humanos e estético-simbólicos ao longo de toda a história. De forma específica, a arquitetura ganha um significado de atividade criadora, responsável pela transformação da forma em função de seu uso e adaptação ao uso do homem e isso em um processo contínuo e continuado ao longo da história.
Para tal, a arquitetura e o urbanismo se definem como a ciência do que considera estes espaços e funções com um propósito específico: o ser humano, ou seja, a arquitetura é a arte de fazer o ser humano viver bem em seu espaço e entorno segundo conceitos de forma estética e uso dos espaços. A arquitetura é orientada para resolução de problemas próprios da habitabilidade do entorno humano. A consciência da arquitetura como problema se desenvolveu como consequência do interesse por proporcionar instrumentos racionais e científicos aos processos projetuais (Martínez, 2000)

Portanto, a metodologia do Taller tem a proposta de resgatar junto as comunidades, uma forma de recriar os espaços habitáveis a partir de uma proposta sustentável que insere o sujeito neste feito, dando-lhe a responsabilidade de manter sua criação para as próximas gerações, tornando-o autor de seu espaço e não simplesmente um ator que sobrevive em um cenário adaptado e sucateado por falta de recursos e planejamento público.

Será relatada neste artigo a experiência vivida na segunda edição do evento, o $2^{\circ}$ Taller Vertical Internacional: La Reina de las Tres Fronteras, que aconteceu de 8 a 18 de setembro de 2015, no bairro Centro de Frederico Westphalen, RS. A definição do termo usado como título "La Reina de las Tres Fronteras" surgiu devido a proposta de internacionalização do autor, enquanto responsável por esta função junto ao Curso de Arquitetura e Urbanismo da Universidade Regional Integrada do Alto Uruguai e das Missões-URI Campus de Frederico Westphalen onde, partiu do pressuposto da localização geográfica da cidade brasileira situada na zona do Cone Sul (região composta por zonas austrais da América do Sul) através dos seguintes países: Argentina, Paraguai e Uruguai.

\section{A metodologia pedagógica do Taller}

Sobre as reflexões dos significados da inserção do Taller como prática acadêmica que compõe o processo ensino-aprendizagem no curso de Arquitetura e Urbanismo, pode-se evidenciar que estas vão ao encontro dos interesses sociais da população e suas necessidades.

O fato de trabalharmos com políticas públicas sociais nos faz lidar diretamente com a cidade em si, criando um conjunto rede de relações que necessitam de instrumentos urbanísticos democráticos para levar entender as necessidades da maioria da comunidade. É o caso das audiências públicas para tomada de decisões que auxiliam as autoridades representativas de uma sociedade. $\mathrm{O}$ arquiteto e urbanista deve estar ciente de que em sua atuação profissional assume o papel de agente da mudança social, cujos resultados deverão refletir de forma positiva nas comunidades, e nos interesses e necessidades sociais da população.

Sendo assim, minhas pesquisas exploratórias acerca da influência exercida pela metodologia pedagógica do Taller na concepção de projetar arquitetura e urbanismo, deixam relatos fantásticos da inter-relação 
entre o pensar e o fazer dentro das oficinas de trabalho durante o período de estudos da região alvo de intervenção. São criações de cenários comunitários com ênfase na socialização dos espaços e priorização do que é sustentável acessível e necessário, equilibrados pelo senso de cidadania inerente a cada sujeito e grupo social envolvido.

Para Schön (2000), toda a teoria deve ser embutida na sua prática, ou seja, o aluno deve ser instruído a fazer e refletir e então assim, aprender. Com isso, ele sustenta a hipótese de que teoria e prática são elementos fundamentais e indissociáveis, ou seja, o ato de aprender está indiscutivelmente vinculado a um conhecimento e sua decorrente experimentação.

A experiência vivida no projeto de intervenção do bairro Santo Antônio (Ver Figura 1) no $1^{\circ}$ Taller Vertical Internacional ${ }^{2}$, ocorrido no período de 15 a 28 de setembro de 2014, na cidade de Frederico Westphalen, situada na região norte do estado do Rio Grande do Sul - Brasil serviu para facilitar a aplicação da metodologia do Taller neste ano de 2015.

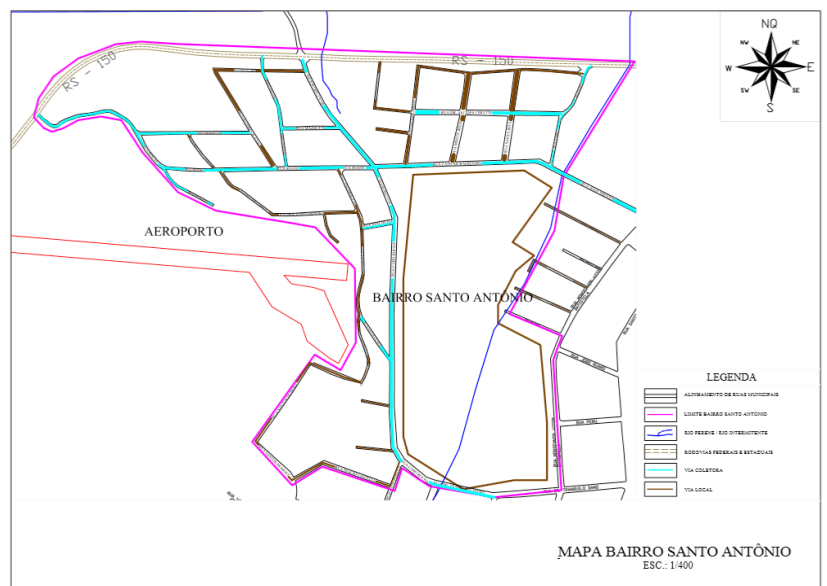

Figura 1. Mapa que situa o bairro Santo Antônio, Frederico Westphalen, RS. Fonte: Diagnóstico realizado para a intervenção no $1^{\circ}$ Taller Vertical Internacional, Curso de Arquitetura e Urbanismo, URI-Frederico Westphalen, 2014

O Taller realizado no bairro Santo Antônio em 2014, segundo Brum, Callai e Graciolli (2015) mostrou à comunidade acadêmica o fiel exemplo de participação cidadã na construção de espaços comunitários. Para os autores, a participação cidadã tem por prioridade a construção conjunta de moradores, estudantes e professores, para uma situação idealizada pela comunidade e adequada aos princípios que regem o projeto arquitetônico e urbanístico.

2 Marco histórico e educacional para a instituição promotora do evento, a Universidade Regional Integrada do Alto Uruguai e das Missões, através do Curso de Arquitetura e Urbanismo, teve o intuito de integrar habilidades e conhecimentos visando projetos arquitetônicos e urbanísticos com a formação de mecanismos projetuais para a promoção e desenvolvimento de projetos urbanos sustentáveis, que possam desenvolver o cunho social e cultural do polígono de atuação: bairro Santo Antônio, com população em média de 1.000 habitantes.
Brum, Callai, Fernandez e Gaida (2015) também comentam que uma das principais experiências adquiridas nesta prática é constatar a participação dos moradores nas audiências públicas realizadas, onde os mesmos têm a oportunidade de relatar suas dificuldades e carências; também, com orgulho de morador da comunidade, relatar suas histórias e a história do seu bairro, demonstrando o desejo de não perder suas identidades como comunidade ao construir a nova proposta de intervenção.

O $2^{\circ}$ Taller Vertical Internacional: La Reina de las Tres Fronteras ${ }^{3}$ aconteceu no bairro Centro de Frederico Westphalen, RS (Ver Figura 2 e Figura 3).

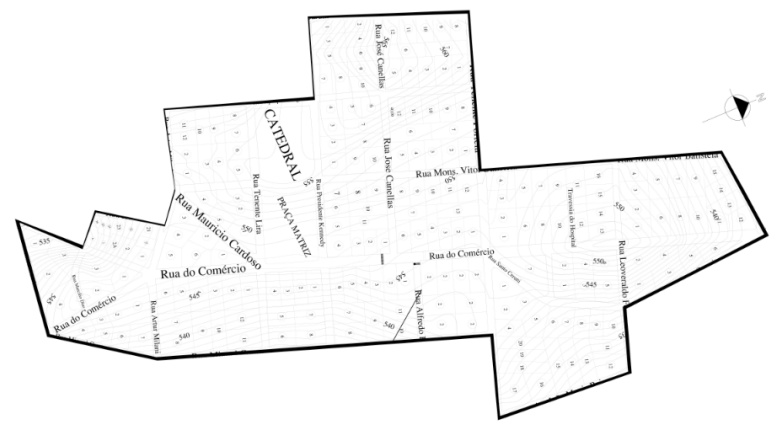

Figura 2. Mapa que situa o bairro Centro, Frederico Westphalen, RS. Fonte: Diagnóstico realizado para a intervenção no $2^{\circ}$ Taller Vertical Internacional, Curso de Arquitetura e Urbanismo, URI-Frederico Westphalen, 2015.

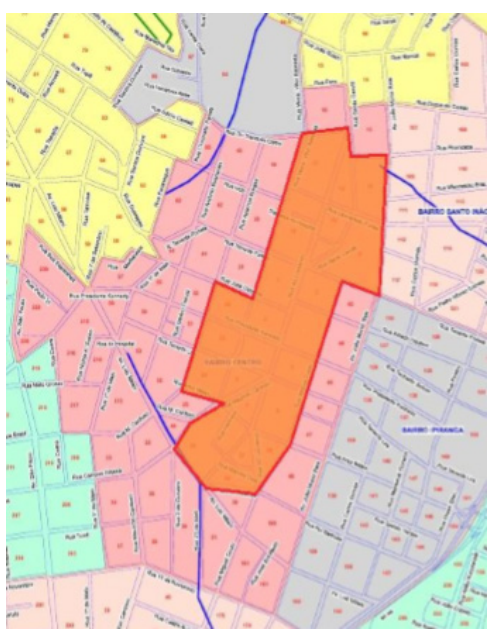

Figura 3. Mapa que situa a área de estudo e os acessos principais e secundários, Frederico Westphalen, RS.

Fonte: Plano Diretor de Desenvolvimento Integrado (PDDI), F W, 2010.

O La Reina de las Tres Fonteras, que contribuiu com a formação de mecanismos projetuais para a promoção e desenvolvimento de projetos urbanos, através de uma linha projetual sustentável e que possam desenvolver o cunho social e cultural do polígono de atuação na área central. Buscou contribuir para a população beneficiária da região selecionada através de projetos arquitetônicos e urbanísticos, fornecer subsídios as autoridades locais e municipais acerca das problemáticas debatidas e fundamentadas através dos partidos propostos. 
$\mathrm{O} 2^{\circ}$ Taller Vertical Internacional realizado no bairro Centro teve o objetivo de propor, mediante a formulação de propostas arquitetônicas, hipóteses de desenho que delimitassem uma reformulação da paisagem social e meio ambiente da área central urbana do bairro localizado na área central da cidade de Frederico Westphalen - Brasil, para a construção de espaços sustentáveis e soluções de conflitos urbanos.

Desta forma, o Taller veio contribuir para a população beneficiária da região selecionada através de projetos arquitetônicos e urbanísticos, fornecendo subsídios às autoridades locais e municipais acerca das problemáticas debatidas e fundamentadas através das propostas arquitetônicas. A ênfase foi resolver as questões emblemáticas de usos e fluxos na área central de Frederico Westphalen que carecem de maior atenção.

Para tal, o estudo se fundamentou nos resultados obtidos em reuniões com os arquitetos e urbanistas da cidade e também nos resultados da aplicação de questionários com moradores, usuários e proprietários de comércios na área de atuação. Também houve a identificação de documentos, projetos e informações que contribuíram para a definição de estratégias projetuais de atuação, com definições de paisagem cultural e social dos recortes urbanos definidos que delimitam diferentes escalas de intervenção, escala social, cultural, ambiental e outras.

A proposta estabeleceu-se como uma perspectiva multi e transdisciplinar, onde os docentes locais, responsáveis pelas oficinas, tiveram a oportunidade de trabalhar conjuntamente com docentes convidados nacionais e internacionais visando à busca de dimensões necessárias para as compreensões das problemáticas nos recortes urbanos selecionados nesta edição 2015

O fato de relacionar diversas escalas de intervenção no polígono de estudo propiciou aos acadêmicos a elucidação de uma situação real específica de projeto arquitetônico e urbanístico. Para tanto foram delimitados elementos urbanísticos, enfatizando a intervenção dos recortes urbanos mediante o lançamento de hipóteses arquitetônicas que incluíram uma visão prospectiva dos impactos gerados. Assim foi então definindo um Programa de Necessidades adequado à problemática local: reestruturação ou reorganização da via pública em estudo; alternativas de estacionamento; áreas de convívio; acessibilidade; espaços colaterais com vistas a uma rota cultural; e ambiência urbana.

O $2^{\circ}$ Taller Vertical Internacional - URI Brasil foi formado por 16 equipes de oficinas organizadas, com estudantes do Curso de Arquitetura e Urbanismo da URI Campus de Frederico Westphalen, bem como de outras instituições de ensino nacionais e internacionais ${ }^{4}$. Os participantes ficaram organizados em quatro grandes equipes subdivididas em quatro grupos

4 Facultad de Arquitectura da Universidad La Gran Colombia (UGC), Colômbia; Universidad Veritas de Costa Rica; Curso de Arquitetura e Urbanismo da Universidade de Passo Fundo (UPF), Rio Grande do Sul. de estudo, cada um com um tema, assim compondo uma unidade ao se complementarem no resultado final da proposta. Estes quatro temas foram delimitados em: vias e mobilidade urbana, vias e mobilidade urbana (apoio), acessibilidade e espaços colaterais.

Foi estabelecido a partir do diagnóstico ${ }^{5}$, um programa de necessidades que ficou assim definido: reestruturação ou reorganização da via (legibilidade, mobilidade e circulação, segurança para o pedestre, iluminação pública); estacionamentos (propor novas alternativas para as áreas de convívio como os Parklets e organização do uso de áreas públicas pelos bares e restaurantes com a compatibilização de usos); acessibilidade (NBR 9050); espaços colaterais (rua dos arcos, área em frente à prefeitura e valorização e preservação dos prédios históricos e culturais com a proposta de uma rota cultural) e ambiência urbana, contemplando os aspectos ambientais, as áreas verdes e arborização, o conforto térmico a partir do sombreamento, iluminação natural e ventos predominantes, poluição visual e sonora.

Como resultado das hipóteses formuladas para este $2^{\circ}$ Taller, efetivou-se propostas arquitetônicas resultantes das oficinas, que cumpriram com rigor as metas específicas que haviam sido estipuladas para o $2^{\circ}$ Taller Vertical Internacional, ou seja, a realização de um estudo prévio do polígono de atuação, neste caso, a área central da cidade de Frederico Westphalen, de maneira que, esperamos que possa servir como ferramenta sustentável e urbanística aos atores envolvidos.

Através destas ações conjuntas, esta segunda edição do Taller pode deixar como legado quatro propostas técnicas capazes de fornecer subsídios às autoridades municipais acerca das problemáticas levantadas e fundamentadas através dos olhares arquitetônicos de estudantes e professores da Argentina, o Brasil, a Colômbia e a Costa Rica.

\section{$2^{\circ}$ Taller Vertical Internacional: reflexões acerca de uma metodologia para a arquitetura}

O $2^{\circ}$ Taller Vertical Internacional em Frederico Westphalen, neste seu segundo ano (2015), veio para mostrar sua identidade e autenticar o seu sucesso. Enquanto em 2014 a sensação era de júbilo e de preocupação, pelo que era novo ainda e pouco conhecido, em 2015 minha sensação como idealizador do evento foi de orgulho pelo produto apresentado às comunidades, e de segurança por ter vivenciado o desenvolvimento

\footnotetext{
5 O Diagnóstico do $2^{\circ}$ Taller Vertical Internacional foi elaborado por 9 grupos de pesquisa com acadêmicos do $8^{\circ}$ semestre na disciplina de Planejamento Urbano I, da seguinte forma: 1- Histórico, síntese e evolução da cidade de Frederico Westphalen; 2- Histórico do Bairro Centro e imagens da cidade; 3- Localização macro, micro e análise da qualidade na pequena escala; 4- Aspectos físicos naturais e ambiência urbana; 5- Cenário atual e cenário legal: legislação e conduta; 6- Acessibilidade no espaço urbano; 7- Vias: análise de mobilidade e circulação; 8- Análise funcional e morfologia do espaço urbano; 9- Leitura comunitária.
} 
de uma prática séria e comprometida. Tanto a comunidade acadêmica como os moradores de Frederico Westphalen, principalmente os usuários da área central desta cidade, poderão ser beneficiados com propostas que logo deverão ser apresentadas as esferas políticas e comunitárias, de forma a instituir um novo referencial para Frederico Westphalen.

Caracterizar o lugar onde se desenvolve este estudo é importante porque, segundo Martinez (2000), o único propósito da arquitetura e o urbanismo ao considerar os espaços e suas funções é o ser humano. A arquitetura é a arte de fazer o ser humano viver bem em seu espaço e entorno segundo conceitos de forma estética e uso dos espaços, uma disciplina orientada para resolução de problemas próprios da habitabilidade do entorno humano (Martínez, 2000).

Castello (2005) diz que a área da Arquitetura e o Urbanismo ingressa e se incorpora decisivamente ao projeto de lugar, e este pode se valer da estratégia de ressaltar os estímulos percebidos de antemão como os mais marcantes do ambiente onde se desenvolve o projeto, fazendo destes os elementos componentes da estrutura ambiental - sejam naturais, culturais, materiais, imateriais.

Com base em documentos e depoimentos de antigos moradores, as informações a respeito da cidade de Frederico Westphalen dizem que o bairro central desta cidade teve início com a construção da estrada geral entre Seberi - Iraí. O Engenheiro Frederico Westphalen projetou a Rua do Comércio com 40 m de largura, assim com várias outras ruas também foram mapeadas por ele, como as ruas Tenente Portela, Monsenhor Vitor Batistela, José Canellas, Siqueira Campos e Antonio Boscardin, feitos deixados por ele até a data de sua transferência para Passo Fundo em 1940. A partir destas obras, o centro da chamada Vila Barril foi se desenvolvendo e, em torno dessas obras, surgiram aos poucos outras construções que se mantiveram de 1930 a 1960, após as antigas construções foram demolidas para dar lugar ao cimento e ao tijolo (Ver Figura 4).
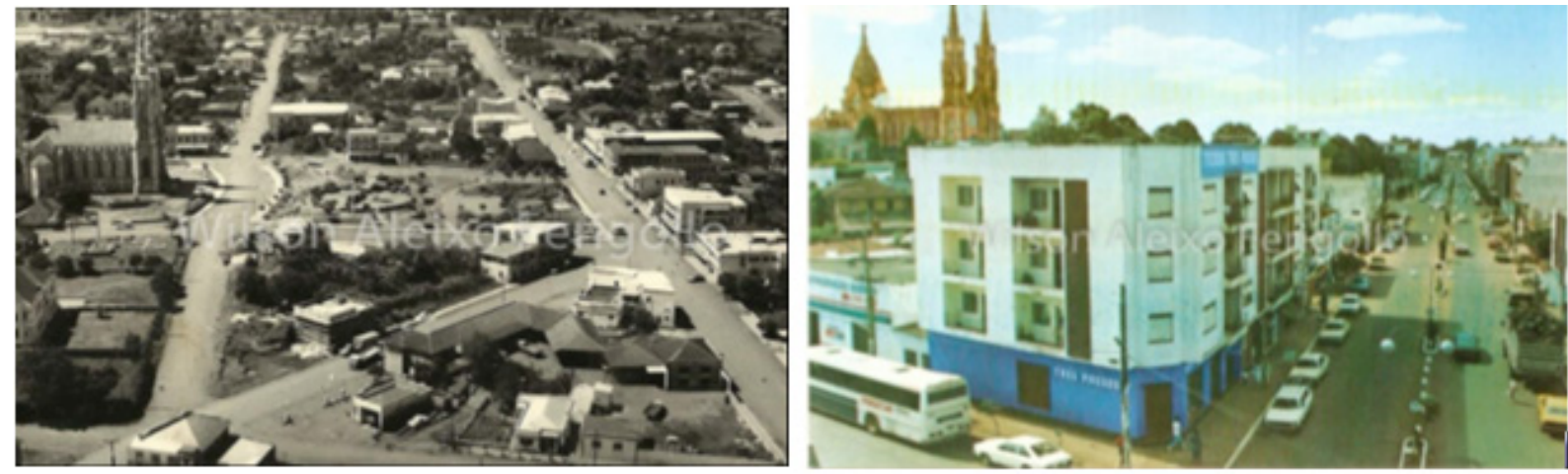

Figura 4. Mapa aéreo do centro de Frederico Westphalen em 1967 e vista da Rua do Comércio, esquina com a rua Artur Milani em 1997. Autor: Wilson Ferigollo

URL: http://www.ferigollo.com.br

Frederico Westphalen é uma cidade que está em pleno desenvolvimento urbano surgindo com este os benefícios e também se originando algumas dificuldades no que se refere ao uso do meio ambiente, provindas de novos usos do espaço geográfico, do aumento populacional, das mudanças culturais impostas pelo próprio desenvolvimento urbano e outros problemas de ordem gerencial. Para melhor entender este processo é que uma das ações do $2^{\circ}$ Taller Vertical Internacional foi a realização de um estudo prévio da área central da cidade, através de reuniões com os arquitetos e urbanistas da cidade e da aplicação de questionários participativos com moradores, usuários e proprietários de comércios na área de atuação.
É importante compreender que as paisagens que podemos ver são o resultado da vida em sociedade, é a busca do homem em garantir sua sobrevivência e satisfação de suas necessidades. Observar e analisar o local são uma forma de saber o quanto este pode ser responsável por limitações ou possibilidades à sociedade (Callai, 2005).

O planejamento caminha junto com a realidade, junto com outros atores, é uma interação técnica que permite uma percepção qualitativa e contextual, partindo do pressuposto de que exista o respeito e a aceitação do intercâmbio de percepções diferentes inerentes à diversidade existente. Desta forma admitem-se a construção de consensos, integrando 
os participantes e apoiando a formação de redes e alianças entre os verdadeiros atores em prol do desenvolvimento, mediante processos de solução (Oliveras, 2007).

Esta leitura solidária deu origem a uma matriz composta por quatro conceitos fundamentais para a tradução do desejo comunitário: Forças, Oportunidades, Fraquezas e Ameaças. Estes conceitos foram inseridos como direcionamento das investigações analisando os seguintes setores: o local, as vias, a segurança, o lazer e a infraestrutura local. A partir deste cruzamento de informações, foram elencadas algumas estratégias e técnicas que de forma antecipada aos estudos projetuais, atuaram como elementos norteadores para a definição de estratégias projetuais de atuação, com definições de paisagem cultural e social dos recortes urbanos definidos.

Esta análise de chances de se obter uma solução adequada para a comunidade envolvida, conta com os pontos fortes e pontos fracos do local em estudo. Os pontos fortes são devidos aos fatores internos e por isso controláveis (Forças), ou devidos aos fatores externos e portanto, incontroláveis (Oportunidades). Os pontos fracos são devidos aos fatores internos e portanto, controláveis, são então chamados de Fraquezas; quando são externos e incontroláveis, Ameaças.

No conceito de Forças, na representação da leitura comunitária, ficaram definidas como problemáticas os lotes baldios, a quantidade de arborização, a topografia, a altura das edificações, o uso e ocupação do solo parcialmente adequado conforme a Zona Comercial Um, o espaçamento das vias com largura apropriada ao trânsito de veículos e o fato de que a Rua do Comércio abriga edificações comerciais, residenciais e institucionais.
Como Oportunidades, foram citados a existência de áreas apropriadas para a expansão comercial, a movimentação do local, o uso do calçadão como comércio temporário, a implementação do Plano Diretor de Desenvolvimento Integrado (PDDI) conforme o estatuto das cidades, a regulamentação da conservação e restauração de prédios com valores históricos e culturais e possíveis edificações culturais e de lazer em terrenos baldios.

Como Fraqueza, a comunidade apurou o trânsito intenso em um mesmo local, o uso residencial em terrenos com valor imobiliário elevado, poucos terrenos para áreas institucionais disponíveis, o uso incompatível de residências em áreas comerciais, a falta de locais para atividades culturais e a altura dos edifícios superiores à máxima permitida no Plano Diretor de Desenvolvimento Integrado (PDDI).

E como Ameaça ficou caracterizada para finalizar os resultados da consulta popular, o trânsito intenso, a falta de ventilação e iluminação zenital devida à aglomeração de edificações muito próximas, o perigo de propagação de incêndio devido à falta de recuo das laterais das edificações e também, os pontos comerciais localizados nesta área, prejudicando o comércio nas periferias.

Após o diagnóstico feito pelos acadêmicos, também foram detectados alguns dos principais pontos negativos da região central (Ver Figura 5), como a falta de estacionamento, problemas de infraestrutura viária, concentração das atividades comerciais e de serviços ao longo da Rua do Comércio, calçadas irregulares, danificadas e inviáveis a circulação de pedestres com mobilidade reduzida nas ruas adjacentes a Rua do Comércio, ausência de rampas de acessibilidade e piso tátil direcional, sendo que as existentes estão em desacordo a NBR: 9050/2004.
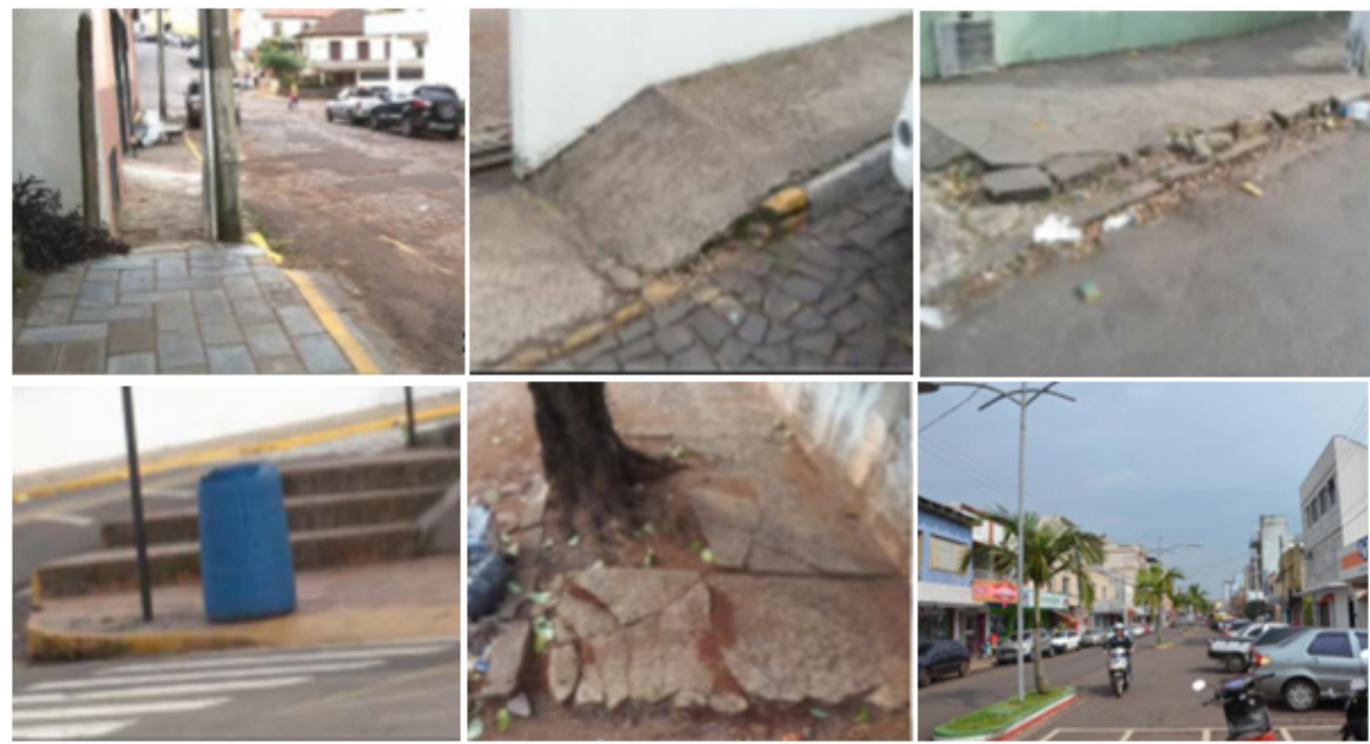

Figura 5. Pontos negativos do bairro apontados no questionário participativo.

Fonte: Diagnóstico de parte do documentário, $2^{\circ}$ Taller Vertical Internacional, Frederico Westphalen, 2015. 
Foram observados vários outros pontos de destaque (Ver figura 6) como a topografia acidentada, existência de toldos e placas publicitárias no espaço destinado a circulação de pedestres, insegurança noturna na região central da praça, ausência de rondas policiais nas ruas próximas a Rua do Comércio, falta de atrativos na região central da praça, ausência de espaços de integração familiar, mobiliário público precário, falta de espaços externos de lazer, ausência de lixeiras com separação de lixo, serviço de coleta de lixo precário nas ruas adjacentes a Rua do Comércio, esgoto mal tratado ocasionando odor desagradável, iluminação pública precária em alguns pontos, falta de arborização, poluição sonora ocasionada por carros de som automotivos e casas de espetáculos, ausência de transporte coletivo, mistura de paisagens como construções de baixa altura entre prédios altos e outros.
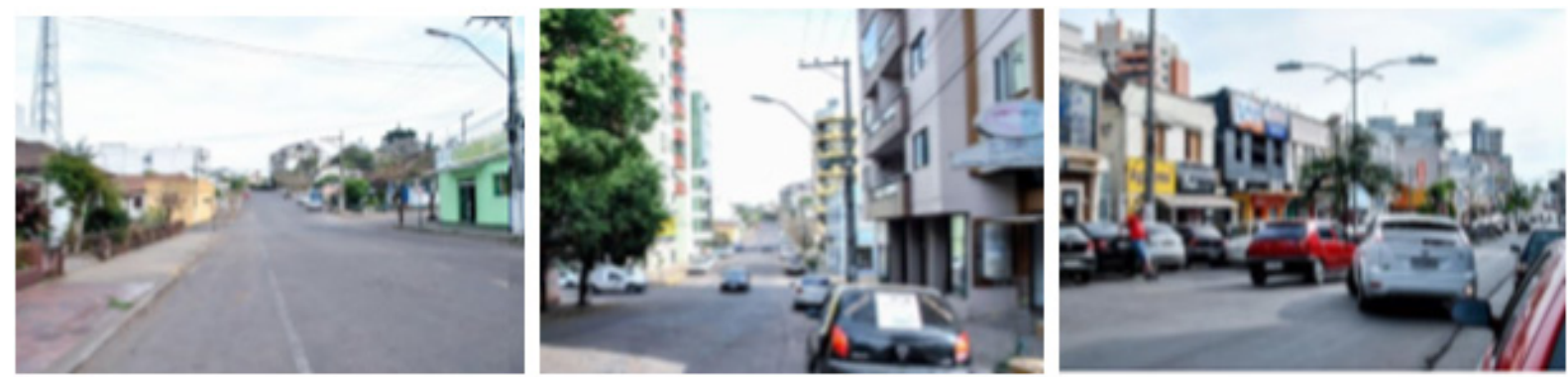

Figura 6. Alguns outros pontos de destaque resultantes do diagnóstico, como a mistura de trechos com residências de baixa altura, trechos com edificações comerciais com muitos pavimentos, e o grande fluxo de veículos na rua do comércio.

Fonte: Diagnóstico feito como parte do documentário do $2^{\circ}$ Taller Vertical Internacional, Frederico Westphalen, 2015.

Com este diagnóstico, constata-se que a comunidade observa, vive e interage seus problemas e anseios em busca de melhores condições de habitar e de viver em seus espaços comuns, tentando construir, a partir de sua visão, um novo espaço. Portanto, é do movimento da sociedade e de sua produção que determinam os espaços geográficos. O lugar tratado aqui é produto do ser humano, pensado por ele e para ele, composto de construções e vidas. Para Castello (2005, p.36), "A urbanidade é uma qualidade típica e única do ambiente construído pelo ser humano".

Com base na construção de uma nova visão de paisagem urbana (paisagem social e meio ambiente) e a busca por um espaço urbano sustentável, em uma dinâmica entre os setores locais, é que o Taller URI Brasil em cada versão busca conhecer as características urbanas e geográficas do lugar de intervenção, em um processo de diálogo com a comunidade.

Neste processo, o arquiteto e urbanista deve de fato se sentir um ator social no contexto real e construindo assim pontes para os lançamentos de propostas, constituindo as 3 etapas da estrutura do Taller: a familiarização com o conceito de paisagem em um entorno urbano; as definições de cenários de atuação no setor da cidade; e o entendimento da proposta urbana desenvolvida através de artefatos arquitetônicos. Este entendimento da proposta urbana é feito com um único objetivo de entender o envolvimento do sujeito com o meio em que habita, com base nas relações que ele desenvolve com este lugar e com as pessoas que estão à sua volta, que também mantém relações e funções em seus espaços.
O espaço urbano habitado pode ser entendido a partir de Santos (1988), que insere o ser humano em seu espaço como um ser social por excelência, onde ele atua de forma dinâmica e uma das formas de revelação desse dinamismo está, exatamente, na transformação qualitativa e quantitativa do espaço habitado. Para Santos (1988) “[...] tanto a paisagem quanto o espaço resultam de movimentos superficiais e de fundo da sociedade, uma realidade de funcionamento unitário, um mosaico de relações, de formas, funções e sentidos" (p.21).

Castello (2005) entende ser a urbanidade uma qualificação vinculada à dinâmica das vivências das pessoas ao fazer uso do ambiente urbano, público, isso em comunicação com esse ambiente onde vive. Então, parece que a urbanidade e o Taller aqui dialogam e fundem-se em benefício do que é público e do povo. Pois Taller é mudança, são propostas de melhorias. Castello (2005) diz que no campo da urbanidade é possível detectar mudanças, no que diz respeito ao âmbito público dos lugares da urbanidade.

O relacionamento funcional e estético de um objeto geográfico com seu entorno, que manifeste todo e qualquer conhecimento de nas dimensões social-psicológica, política, econômica, histórica, etc., para Souza (2008) é de responsabilidade do arquiteto. Com essas dimensões é que o autor defende um desenvolvimento que considera os problemas ecológicos e sociais inseridos no contexto capitalista, pois é inegável esta interdependência. 
Para Souza (2008), referir desenvolvimento como uma forma de mudança, pode não ser aceito por grupos sociais com valores culturais próprios e por sua vez com particularidades histórico-geográficas. $\mathrm{O}$ autor coloca que, se desenvolvimento é definido como mudança, logo esta deverá ser para melhor. Porém, ele se refere ao caso em que o desenvolvimento possa assumir a forma de uma mudança que traga efeitos colaterais, e então não caracterize mais um desenvolvimento. Porém, desconsiderando esta abordagem negativa, para Souza (2008), um autêntico processo de desenvolvimento socioespacial é aquele em que se consegue constatar uma melhoria da qualidade de vida e um aumento da justiça social.

Nesta discussão, Souza (2008) referenciou melhoria da qualidade de vida e um aumento da justiça social para definir o desenvolvimento socioespacial. Logo, para melhoria da qualidade de vida, o autor trata como a crescente satisfação das necessidades básicas e não básicas, assim como necessidades materiais e imateriais de uma parcela cada vez maior da população. Já para o que se refere à justiça social, esta vai depender de uma grande multiplicidade de entendimento da ideia de justiça social, e este é um debate que demanda várias referências. $O$ objetivo de aumento da justiça social contextualiza o objetivo de melhoria da qualidade de vida, ambos são imprescindíveis.

A participação na vida pública para Torricelli (2015) não é nova. Para o autor, pensar no coletivo é uma prática muito antiga, sua grande novidade está no que se refere ao planejamento urbano. Na verdade, os responsáveis pelo planejamento urbano se reúnem por aproximadamente meio século e falam sobre participação cidadã na construção das cidades, porém muitas vezes estes planejadores parecem crer que a temática é uma coisa nova. Mas sabemos que não é novo, porém a novidade está na ampliação das oportunidades de participação, que podem ter se ampliado através do desenvolvimento de recursos como a internet e redes sociais, que se posicionam como reais aceleradores sócias, precisamente no campo do desenvolvimento territorial e do urbanismo (Torricelli, 2015). Mas supõe também a diminuição da pobreza e a ascensão social e econômica de parcelas da população que ainda estão marginalizadas.

Para Torricelli (2015), no que se refere a participação, devemos lembrar que participar envolve a capacidade de discutir e também de chegar a compromissos. Pode ser considerada como um elemento central, porém é apenas um elemento a considerar na questão do direito à cidade. Este direito é um direito especificamente coletivo, pois todos têm o direito de transformar a cidade e de viver a cidade, por isso a importância de envolver a todos em busca da construção solidária do espaço urbano.

\section{Considerações}

Para Romero e Mesías (2004), a solução dos problemas urbanos e da habitação deverá mobilizar todos os setores da sociedade e ser um ponto de concorrência para a participação ativa. Deverá ser um espaço de diálogo e negociação entre as várias partes interessadas, como a população organizada, a governança local e central, as organizações não governamentais (ONG), o setor empresarial e a cooperação internacional. Conhecer os sujeitos é importante, mas não o suficiente. É preciso assegurar suas inter-relações e articulações de tal modo que, muito além da formação de pequenos grupos, de partidarismos políticos, do paternalismo e clientelismo, possam se criar e se fortalecer redes sociais para a construção de cidades socialmente sustentáveis (tradução nossa).

O Taller é uma forma de inserir a Arquitetura e o Urbanismo na realidade social, onde o fazer científico se mistura e se entrelaça com o viver da comunidade, entendendo seus apelos e necessidades. A partir da técnica, criando propostas urbanas sustentáveis e entendendo de vez por todas, é que a arquitetura é pensada e idealizada para todas as pessoas, independendo das condições econômicas ou situação social. Portanto, os problemas urbanos surgem em qualquer contexto e atinge a rotina de todos os sujeitos independentemente de sua habitação estar ou não em condições de habitabilidade.

O melhor deste processo de planejamento em busca de desenvolvimento é a expectativa de que para a expressão dos resultados sobre a nova forma de participação cidadã no Taller de Arquitetura, como foi o caso do $2^{\circ}$ Taller vertical Internacional, tenhamos como aliado a própria realidade dos fatos. Neste sentido, além de mudanças físicas em um lugar, fica a nova proposta de vida para os habitantes, onde eles passam a ser responsáveis pelas suas vidas e pela coletividade, desfrutando dos benefícios do que é novo e bom, porém continuando a carregar os fardos de sua história. Contudo, este fardo agora terá a configuração de "responsabilidade pelo adquirido", de orgulho pelos vínculos locais e respeito por si e pelo outro, agora donos de seus espaços vivos.

\section{Referências}

Brum, C., Callai, H. \& Graciolli, D. (2015). O Taller como instrumento de cidadania. Anekumene, (6), 21-30.

Brum, C., Callai, H., Fernandez, M. \& Gaida, C. (2015). Uma nova participação cidadã em Talleres de Arquitetura: Caso do Bairro Santo Antônio. Salão Conhecimento.

Callai, H. (2005). Aprendendo a ler o mundo: a geografia nos anos iniciais do ensino fundamental. Cad. Cedes, 25, (66), 227-247. Disponível em: http://www.cedes.unicamp.br/

Castello, L. (2005). Repensando o lugar no Projeto Urbano. Variações na percepção de lugar na virada do milênio (1985-2004) (tese de doutoramento). Universidade Federal do Rio Grande do Sul, Porto Alegre, Brasil.

Ferigollo, W (2013). Mapa aéreo do centro de Frederico Westphalen em 1967 e vista da Rua do Comércio, esquina com a rua Artur Milani em 1997. [Foto]. Disponível em: http://www.ferigollo.com.br/

Harvey, D. (2013). Ciudades rebeldes: del derecho de la ciudad a la revolución urbana. Madrid, España: Akal. 
O Taller como prática do processo de cidadania

Cristhian Moreira Brum

Martinez, A. (2000). Ensaio sobre o projeto. Brasília, Brasil: Universidade de Brasília.

Oliveras, R. (Ed.). (2007). Herramientas de planeamiento participativo para la gestión local y el hábitat. La Habana, Cuba: Programa Iberoamericano de Ciencia y Tecnología para el Desarrollo CrTED.

Romero, G. \& Mesías, R. (Coord.). (2004). La participación en el diseño urbano y arquitectónico en la producción social del hábitat. México: Programa Iberoamericano de Ciencia y Tecnología para el desarrollo CYTED.

Sánchez, J. D. (2012). Taller de proyecto arquitectónico I. México: Red Tercer Milenio.
Santos, M. (1988). Metamorfoses do espaço habitado: fundamentos teóricos e metodológicos da geografia. São Paulo, Brasil: Hucitec.

Schön, D. (2000). Educando o profissional reflexivo: um novo designe para o ensino e a aprendizagem. Porto Alegre, Brasil: Artmed.

Souza, M. L. de. (2008). Mudar a cidade: uma introdução crítica ao planejamento e à gestão urbana. (5 ed.). Rio de Janeiro, Brasil: Bertrand Brasil.

Torricelli, G. (Marzo de 2015). Espacio público y ciudadanía en la era global. En: Seminario de Doctorado. Área de Geografía. Facultad de Filosofía y Letras, Universidad de Buenos Aires, Argentina. 